\title{
Blood Pressure in Schoolchildren and Adolescents and its Variation according to Nutritional Status Evaluation: An Early Preventive Key for Obesity Comorbidities
}

\author{
Bosch VM, Moya M*, Espejo MP, Gutierrez J and Meca J \\ University of Murcia and University Miguel Hernández, Alicante, Spain
}

Received: : July 02, 2015; Accepted: August 29, 2015; Published: September 18, 2015

*Corresponding author: Manuel Moya, Emeritus Professor of Pediatrics, University Miguel Hernández, Campus de S. Juan, Alicante Spain, Email: manuel.moya@umh.es

\begin{abstract}
Background: Cardiovascular diseases (CVD) already exist in pediatric ages although their progress and major clinical burden occur in adulthood. Wide international studies have shown their tracking from early ages. Elevated blood pressure (EBP) is more frequent in overweight and obese children and adolescents $(\mathrm{C} \& \mathrm{~A})$, although this is often overlooked, particularly in slightly overweight children. The aim of this study is to screen the asymptomatic C\&A in order to stress the importance of it.
\end{abstract}

Methods: 1347 C\&A (45\% girls) regularly attending urban and suburban state schools with ages between 6-18 years were enrolled after having relevant inclusion criteria. Gender, age, height, weight and circumferences were obtained with a specified precision limits for each one. The nutritional status was after BMI-Z score. Blood pressure measurements were also taken with the same strict patterns using mercury column devices. Prehypertension was considered when systolic or diastolic blood pressure (SBF, DBP) were higher than $90^{\text {th }}$ centile and below the $95^{\text {th }}$ centile.

Results: SBP $>90^{\text {th }}$ centile was founded in $25.7 \%$ of the whole sample and in $31.9 \%$ of the overweight and obese subgroups. Overweight C\&A were $24 \%$, and obese $8 \%$ of the total populations, these ratios unfortunately are concordant to the skewed national pediatric population. Significant differences occur when subgroups were analyzed by nutritional status, gender and age. The multiple regression analysis shows a clear association of SBP (dependent variable) with age, waist circumference and gender.

After the evaluation of these data it would be of great interest to standardize as much as possible the anthropometric indexes in order to properly assess the nutritional status, even using the $\mathrm{Z}$ score methods can over or underestimate the overweight situation, delaying preventive actions. This has been evident when applying them to this same population, with such high prevalence of overweight and subsequent pre hypertension, which in most cases was unknown by parents. For the correct identification of pre hypertension the auscultatory methods are not the ideal ones due to the inherent subjectivity they imply particularly when assessing DBP, which is later, affected but having an important pathogenetic role in CVD.

\section{Background}

Cardiovascular diseases and pediatric obesity should be considered as a risk situation for adult life [1] but also for the present alterations already in the pediatric patient. Blood pressure elevations are certainly the tip of the iceberg that should lead us to assess and act on this initial condition. This is perhaps different from primary hypertension which is normally treated in the hypertension units. In previous publications $[2,3]$ we analyzed the tracking of cardiovascular diseases (CVD) from pediatric ages, therefore, we now add two new epidemiological aspects. The first is related to the data that forecast that overweight children are at increased risk of becoming obese adults which may lead to shorter life expectancies in the current generation of children compared to their parents [4]. The second comes after well-designed studies in different parts $[5,6]$ in which overweight adolescents have risks of 2.7 or greater for suffering from Elevated Blood Pressure (EBP). Once at this point it is worth adding how this problem will become greater [7] as the increasing prevalence of obesity is not being curved in the next decade.

To the well-known silent cardiovascular alterations in pediatric ages [3], it is important to consider the Iceland-study [8] on target-organ damage when estimated at a mean of 58 years of age. There is a significant correlation between both coronary disease and adult hypertension with adolescents' blood pressures $\geq 95^{\text {th }}$ centile.

EBP in children \& adolescents is of concern not only because of its association with even subtle overweight but also for the involved mechanisms. The role of sympathetic nervous system in the modulation of sympathetic cardiovascular system is evident and although requiring a highly specific technique, it is a field to be worked on [9]. In the last decade [10], a relationship between cardiovascular phenotypes with healthy and overweight youths was established. This could mark the starting point of epigenetic studies on this particular problem of EBP, because not all the obese children \& adolescents develop hypertension or CVD. Epigenetic marks are tissue specific and basically comprise DNA-methylation and histone modifications that in turn will modulate the gene expression. The obesity appearing in Albright hereditary osteodystrophy is the classic example and it is now known that the cause is the disruption of the imprinting GNAS gene [11], but in common obesity, these types of alterations are 
not yet described. Obese mothers tend to have obese children [12] and the interventions to cause maternal weight loss can reverse this effect [13]. Possible disturbances of methylation may arise during fetal development due to the lack of bioavailable methyl donors [14]. However from these hypotheses, the way to ascertain the involved mechanisms exists due to the Human Epigenome Project (www.epigenome.org). This is a part of the future for improving knowledge on hypertension genesis.

The study of EBP as a comorbidity of pediatric overweight is now more common but it has not got the clinical consideration that it deserves particularly when in front of us are a so-called healthy population of children and adolescents. Therefore, the aim of the present study is to adequately screen asymptomatic children and adolescents and evaluate the influence of the spreading overweight when it is evaluated with different anthropometric indices.

\section{Methods}

\section{Subjects}

1347 (out of 48641) children and adolescents, 45\% girls, regularly attending state schools were enrolled in the study. Inclusion criteria were: absence of acute or chronic disease including abnormal puberty stages, providing informed consent signed by parent(s) and required dietary and physical activity questionnaires. Their age ranged between 6-19 years, but they were allocated into two groups: 1 (6-10 years) and 2 (11-18 years) due to puberty onset, growth acceleration and subsequent BMI change.

\section{Data from the sample}

Gender and age (present date-birth date) was primarily obtained. Anthropometrics include: height (precision of $1 \mathrm{~mm}$ ), weight (precision of $100 \mathrm{~g}$ ), and waist circumference (precision of $1 \mathrm{~mm}$ ) [Table 1]. All measurements were taken in the school, in an appropriate room and by the same team. The anthropometric used index was the Body Mass Index-Z score obtained from the CDC standards [15]. Other anthropometric indexes CDC- LMS Zs [15] and International Obesity Task Force Cole curves [16] were used but only for inter comparison on the same population.

\section{Blood pressure measurements}

On the non-dominant armonly auscultatory technique with a mercury column device (Nova Presameter precision of $2 \mathrm{~mm}$ $\mathrm{Hg}$ ) was used, the cuffs were of two sizes ( $9 \mathrm{~cm}$ and $12 \mathrm{~cm}$ wide). The room was quiet, more than 30 ' after the last food intake or moderate physical activity and the void bladder. Measurement of BP [17] was on the right arm preceded by the measure of heart rate through the radial pulse, then fixing of the pulse abolishing point, maximum inflate (20 $\mathrm{mm} \mathrm{Hg}$ above pulse abolishing point) and determine as Systolic Blood Pressure (SBP) when the first sound was heard (Korotkoff phase I) and Diastolic (DBP) coincidental with the last audible sound (Korotkoff phase V). This procedure was repeated 2-3 times and results were averaged. The cases with audible sounds down to zero $\mathrm{mm} \mathrm{Hg}$ were discarded from the blood pressure study. For the study group, the $90^{\text {th }}$ centile was obtained through the methods of computation of blood pressure percentiles for arbitrary sex, age and height given by the Working Group on High blood Pressure that allows the Z score of blood pressure of each individual and $90^{\text {th }}$ centile is considered when the $\mathrm{Z}$ score is greater than 1.282.

Multiple regression analysis, Enter method, estimated the effect of the independent variables on SBP and DBP.

\section{Results}

In Table 2, the BP data (mean \pm SD) of the whole sample appear but also the percentiles 90 according to gender and age. These percentiles can act as a threshold [18] for further evaluation through the Working Group on High Blood Pressure in children

Table 1: Anthropometric data from 1347 children and adolescents according to age and gender (m \pm SD).

\begin{tabular}{|c|c|c|c|c|c|c|c|c|}
\hline AGE (Y) & \multicolumn{7}{|c|}{ BOYS } & \multicolumn{3}{|c|}{ GIRLS } \\
\hline & $\mathrm{N}$ & $\begin{array}{c}\text { Weight } \\
(\mathrm{kg})\end{array}$ & $\begin{array}{c}\text { Height } \\
(\mathrm{cm})\end{array}$ & BMI-Zs & $\mathrm{N}$ & $\begin{array}{c}\text { Weight } \\
(\mathrm{Kg})\end{array}$ & $\begin{array}{c}\text { Height } \\
(\mathrm{cm})\end{array}$ \\
\hline 6 & 48 & $26 \pm 4.8$ & $121.1 \pm 5.1$ & $0.959 \pm 0.884$ & 39 & $23.2 \pm 4.1$ & $118.1 \pm 7.1$ & $0.481 \pm 0.970$ \\
\hline 7 & 74 & $29 \pm 6.2$ & $126.8 \pm 5.2$ & $0.874 \pm 0.830$ & 57 & $27.4 \pm 6.2$ & $123.4 \pm 5.7$ & $0.770 \pm 0.865$ \\
\hline 8 & 67 & $32.6 \pm 6.8$ & $132.5 \pm 6.5$ & $0.860 \pm 0.866$ & 39 & $30.8 \pm 6.2$ & $130.6 \pm 6.6$ & $0.455 \pm 1.56$ \\
\hline 9 & 51 & $34.5 \pm 7.2$ & $136.6 \pm 6.7$ & $0.590 \pm 0.940$ & 51 & $33 \pm 7.2$ & $133.8 \pm 6.9$ & $0.905 \pm 0.905$ \\
\hline 10 & 61 & $40.7 \pm 9$ & $141.5 \pm 6.8$ & $0.864 \pm 0.998$ & 53 & $39 \pm 9.6$ & $141.4 \pm 7.4$ & $0.447 \pm 1.22$ \\
\hline 11 & 62 & $45.7 \pm 10.8$ & $146.9 \pm 7.6$ & $0.901 \pm 0.870$ & 48 & $45.9 \pm 9.7$ & $148.5 \pm 7.8$ & $0.694 \pm 0.994$ \\
\hline 12 & 57 & $49.4 \pm 11.4$ & $151 \pm 7.4$ & $0.778 \pm 0.967$ & 47 & $49.6 \pm 10.3$ & $152.5 \pm 5.9$ & $0.618 \pm 0.931$ \\
\hline 13 & 62 & $56.9 \pm 11$ & $160.7 \pm 8.6$ & $0.771 \pm 0.766$ & 52 & $53.7 \pm 9.8$ & $156.2 \pm 6.7$ & $0.647 \pm 0.862$ \\
\hline 14 & 79 & $59.6 \pm 11.4$ & $167 \pm 6.6$ & $0.375 \pm 0.933$ & 41 & $54.7 \pm 6.6$ & $159.3 \pm 5.6$ & $0.474 \pm 0.547$ \\
\hline 15 & 58 & $63.7 \pm 11.5$ & $169.2 \pm 6.7$ & $0.447 \pm 0.797$ & 45 & $56.4 \pm 9$ & $159.6 \pm 5.7$ & $0.395 \pm 0.769$ \\
\hline 16 & 33 & $67.2 \pm 11.3$ & $172.9 \pm 6.8$ & $0.322 \pm 0.874$ & 44 & $58 \pm 7.1$ & $161.8 \pm 6.2$ & $0.332 \pm 0.637$ \\
\hline 17 & 55 & $69.4 \pm 10.7$ & $173.9 \pm 6.2$ & $0.282 \pm 0.899$ & 59 & $59 \pm 110.6$ & $161.6 \pm 6.5$ & $0.273 \pm 0.701$ \\
\hline 18 & 26 & $71.9 \pm 11.4$ & $175.7 \pm 8.3$ & $0.193 \pm 0.841$ & 39 & $58.9 \pm 8.5$ & $161.7 \pm 5.6$ & $0.139 \pm 0.868$ \\
\hline
\end{tabular}


Table 2; Systolic (SBP) and Diastolic Blood Pressure (DBP) of the whole sample $(\mathrm{n}=1347)$ according to gender $(\mathrm{m} \pm \mathrm{SD})$. The last two columns in each subgroup refer to the blood pressure values $>90^{\text {th }}$ centile in children and adolescents whose height was on the $5^{\text {th }}$ centile, I e the worst condition thus indicating further evaluation.

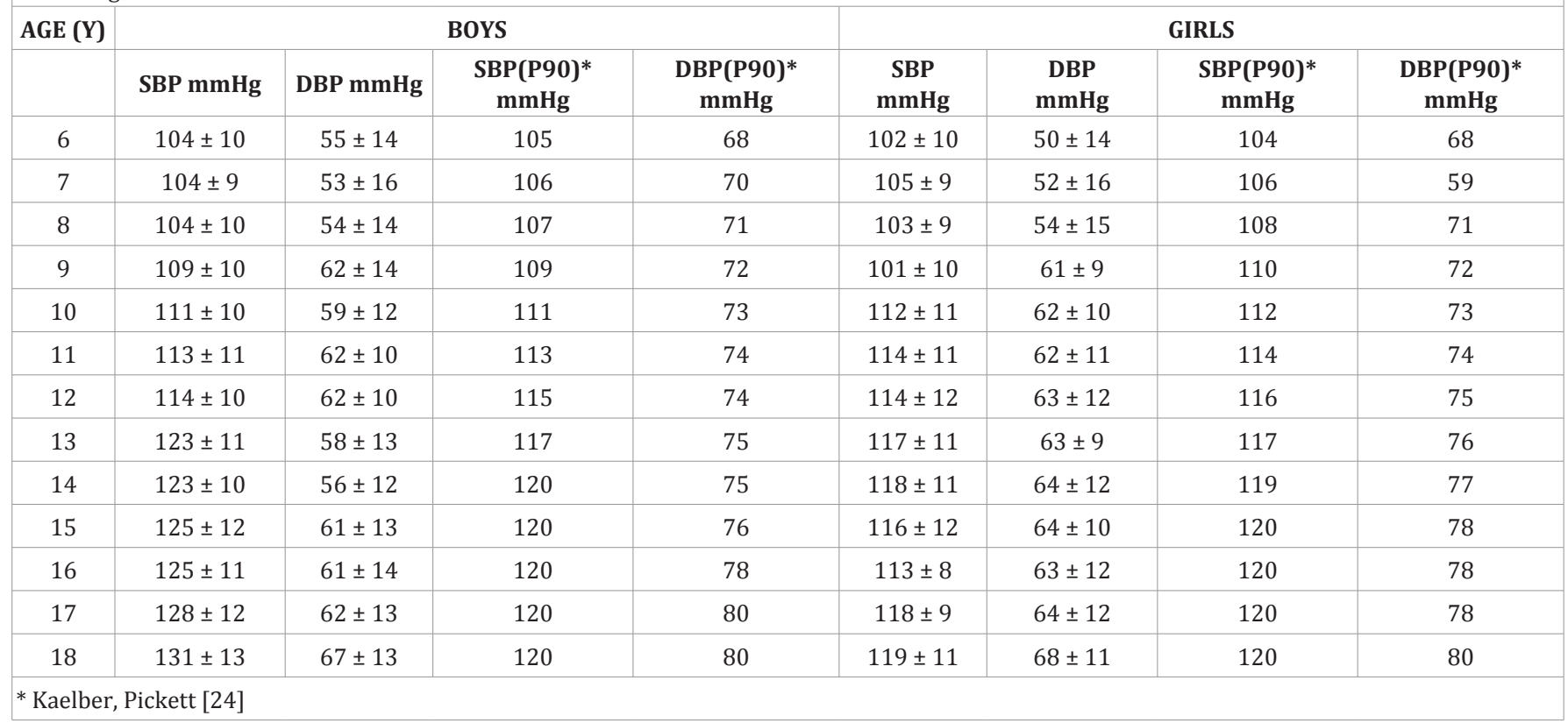

Table 3: Nutritional status of the whole sample according to the BMI- Z score [15] with the absolute number and percentage for underweight, normal weight, overweight and obese.

\begin{tabular}{|c|c|c|c|c|}
\hline \multirow{2}{*}{} & \multicolumn{2}{|c|}{ GROUP 1 (6-10 Y) } & \multicolumn{2}{c|}{ GROUP 2 (11-18 Y) } \\
\cline { 2 - 5 } & Boys & Girls & $15(3.5 \%)$ & $12(3.2 \%)$ \\
\hline $\begin{array}{c}\text { Underweight } \\
<-1 \text { SD }\end{array}$ & $5(1.7 \%)$ & $9(3.9 \%)$ & $301(70 \%)$ & $289(77.1 \%)$ \\
\hline $\begin{array}{c}\text { Normal weight } \\
-1 \text { SD to +1 SD }\end{array}$ & $177(58.8 \%)$ & $150(63 \%)$ & $70(16.3 \%)$ & $56(14.9 \%)$ \\
\hline $\begin{array}{c}\text { Overweight } \\
+1 \text { SD to +2 SD }\end{array}$ & $54(17.9 \%)$ & $47(19.7 \%)$ & $44(10.2 \%)$ & $18(4.8 \%)$ \\
\hline $\begin{array}{c}\text { Obese } \\
>+2 S D\end{array}$ & $65(21.6 \%)$ & $32(13.4 \%)$ & $430(100 \%)$ & $375(100 \%)$ \\
\hline ALL & $301(100 \%)$ & $238(100 \%)$ & \\
\hline
\end{tabular}

Table 4: Multiple regression analysis (Enter method) for SBP and DBP as dependent variables.

\begin{tabular}{|c|c|c|c|c|c|c|c|}
\hline \multicolumn{2}{|c|}{ SBP } & \multicolumn{3}{c|}{ DBP } \\
\hline Model & Beta & t & $\boldsymbol{p}$ & Model & Beta & t & \multicolumn{1}{|c|}{$\boldsymbol{p}$} \\
\hline (Constant) & & 26.142 & 0.000 & (Constant) & 0.408 & 0.000 \\
\hline Age & 0.409 & 11.176 & 0.000 & Age & 0.189 & 4.192 & 0.000 \\
\hline Gender & -0.105 & -4.586 & 0.000 & Gender & 0.119 & 4.161 & 0.000 \\
\hline Waist C. & 0.272 & 6.426 & 0.000 & Waist C. & 0.137 & 2.608 & 0.009 \\
\hline BMI-Zs & 0.000 & 0.002 & 0.998 & BMI-Zs & 0.022 & 0.480 & 0.631 \\
\hline
\end{tabular}

\& adolescents $4^{\text {th }}$ Report [19] and clinical study. The proximity of SBP means could give an idea about this sample quality, whereas DBP means were $13 \mathrm{~mm} \mathrm{Hg}$ lower than Ingelfinger P 90th. The frequency of prehypertension ( $>90$ centile) in the whole population was $346(25.7 \%)$ for SBP and $88(6.5 \%)$ for DBP and in the overweight subgroup for SBP, 143 (31.9\%) and for DBP,
$35(8.2 \%)$

The BMI-Z score data of the two age groups (I and II) are shown in Table 3. The frequency of underweight was scarce. The vast majority corresponds to the normal weights as it was a population normally attending schools and it is worth signaling 


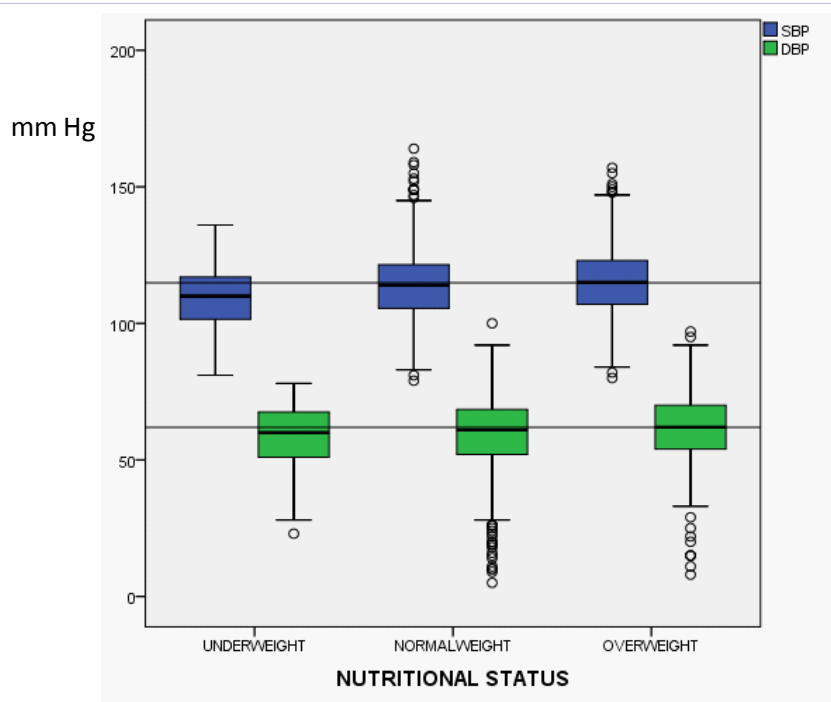

Figure 1: Whole sample box plot for SBP and DBP according to the nutritional status: Underweight, normal weight and overweight (comprises overweight and obese).

the important quota of the overweight and obese children and adolescents.

The multiple regression analysis in the whole sample (Table 4) shows the association of SBP and DBP with constant, age, gender, waist circumference and BMI Z score although other related variables were also analyzed. The standardized Beta coefficient was chosen because the independent variables were not in the same kind of units. As regards gender, 1 denotes male and 2 female, therefore it is possible to signal positivity or negativity of Beta coefficient. Individual regression coefficient ( $t$ ) denotes the significance of the association.

In Figure 1, the box plot of the whole population classified as underweight (UW, $n=62)$, normal weight $(N W, n=834)$ and overweight including obesity (OW, $\mathrm{n}=451$ ) shows a reasonable variation with very little degree of dispersion and of skewness in all three subpopulations. In this, medians for SBP (upper cages) only showed in underweight a lower value than that of normal weight group. The same considerations apply to DBP (lower cages) and only the overweight group showed a little elevation in respect to the reference group. Considering the whole population only in females and for SBP there was a significant difference ( $p$ $<.001)$ among under and overweight. As regards the influence of age in the group 1 (6-10 years) SBP was significantly $(p<.005)$ different between under and overweight in both genders. In the group 2 (11-18 years) the only significant difference $(p<.001)$ occurred for SBP between under and overweight females. Later on these differences will be commented on.

In Table 5 in both genders the absolute number and percentage of UW, NW and OW appears. But according to three different classification criteria for nutritional status: CDC BMIZs; CDC-LMS and Cole curves widely used as recommended by the International Obesity task Force. Because the anthropometric data belong to the same children and adolescents it is worth signaling that in underweight the differences of frequency are not striking, but when considering the overweight subpopulation the proportion of subjects being in this category can almost double. This artificial 'different prevalence' can be an obstacle for assessing overweight as a comorbidity risk.

\section{Discussion}

The early preventive actions for cardiovascular diseases are justified by the fact of its increased global deaths of $41 \%$ between 1990 and 2013 despite a 39\% decrease in age-specific death rates, whether in low, middle or high income countries [20]. If hypertension in pediatric ages is associated with heart failure, coronary disease and deaths before 55 years of age [21], the studies about screening for elevated blood pressure in children and adolescents are required at present [22].

The occurrence of prehypertension in the whole sample (SBP $>90$ centile of the US Preventive Service Task Force [23]) was of $25.7 \%$, higher than that obtained for the US youths, but if we take the DBP cut off limits then the occurrence drops to $6.6 \%$. This difference is hardly acceptable, the high proportion of overweight (19.8\%) could be an explanation due to the forwarded action on SBP, but the technique itself despite the measurement policies cannot be ignored. Another more speculative reason could be the predominance of Mediterranean diet in school lunches. It is worth noting that in all these non-false positive cases the elevated blood pressure was unknown by the family, which in turn and in a majority of instances informed that blood pressure had not been measured before.

The multiple regression analysis in the whole sample (Table 4) signals that the greater effect (Beta and individual regression coefficient) in order of importance on SBP of the independent variables were forage $(0.41 ; 11.2)$, waist circumference $(0.27$; $6.42)$ and gender $(-0.11 ;-4.58)$. For DBP none of them showed significant effect. If in this study waist circumference is removed, then BMI- Z score becomes significant $(0.18 ; 8.48)$. Due to the cross-sectional character of this study, it is not possible to see the long- term consequences of these moderate elevations of blood pressure, but according to the quoted data [1] after following more than 275000 youths for more than 25 years, the negative issue is evident.

Another aspect of interest is the comparison of SBP and DBP means in the subgroups by gender and the ones by age (6-10 $y$ and 11-18 y) considering the gender also in them. All the significant differences occurred in SBP except in the 6-10 year boys group, in which DBP were between under and overweight $(p=0.038)$. Can this fact be related to: the high proportion of overweight in our sample with a significant higher proportion of prehypertension $(X 2=20.3 p<0.000)$; to the lesser values for DBP of our whole sample when compared to the $90^{\text {th }}$ centile obtained from Working Group [19] and that of Kaelber et al. (24) was later simplified by Ingelfinger [18], or perhaps due to the variability of the mercury column device and particularly to the subjectivity they imply and the frequent persistence of the $5^{\text {th }}$ Korotkoff sound [25] , but these cases have been eliminated from the study. 
Table 5: Different prevalence rates of nutritional status for the same population when evaluated through different methods: CDC- Zs; CDC (LMS) - Zs [15] and IOTF-Cole curves [16].

\begin{tabular}{|c|c|c|c|c|c|c|}
\hline & \multicolumn{3}{|c|}{ BOYS $(n=734)$} & \multicolumn{3}{|c|}{ GIRLS $(n=613)$} \\
\hline & BMI zs CDC & BMI zs LMS CDC & IOTF & BMI zs CDC & BMI zs LMS CDC & IOTF \\
\hline Under weight & 2.9 & 3.7 & 1.9 & 3.4 & 5.7 & 3.1 \\
\hline Normal weight & 65.1 & 59.7 & 63.6 & 71.7 & 64.5 & 67.9 \\
\hline Over weight & 17 & 30.4 & 24.9 & 16.8 & 27.4 & 22.8 \\
\hline Obese & 14.9 & 6.1 & 9.5 & 8.1 & 2.4 & 6.2 \\
\hline ALL & 100 & & & 100 & & \\
\hline
\end{tabular}

As seen above pediatric overweight and central obesity are associated with elevated blood pressure, therefore precise evaluation of the individual nutritional status is highly recommendable. The problem is the wide array of anthropometric indexes, most of them developed locally in the past century favoring a certain disparity in this important assessment. Fortunately, the globalization trend has promoted international indexes that can be used all over the world due to their designs. The standards from Cole [16], WHO [26] and in some ways those from CDC [15] have shown that differences in different parts of the world are of not great extent and can be used globally. The last achievement in this trend is the global charts for newborns [27]. This improved methodology will probably give uniformity of data thus avoiding the differences we found in the present study, where the same population can have a double rate of overweight depending on the method used.

Prehypertension or even hypertension cannot be considered alone as precursors of cardiovascular disease with all its later consequences. In normal weight and obese adults [28] and after euglycemic-hyperinsulinemic clamp there was not greater cardiometabolic risk for them insofar as they showed normal insulin sensitivity. This together with the better known experiences about insulin resistance and its associated risks for CVD in adults [29] or pediatric ages [30] should lead to a more efficient search for fasting insulin levels or better for the whole metabolic syndrome factors in all of the overweight people with elevated blood pressure [31], which would imply an earlier preventive intervention. This approach is more practical at the present time, whereas at a more long- term the applied epigenetic studies whether for changes or for variants will be of growing interest. The inherited although not permanent changes (DNA epigenetic markers, mainly $5 \mathrm{mC}$ ) that could appear in obese families do not have the same degree of development as occurs presently in some type of cancers or immune disorders.

As a summary, it can be said that the risen blood pressure in overweight children and adolescents is probably more frequent than expected with short- and long- term undesirable effects. It is true that in some areas of the world, obesity prevalence is decreasing so is the frequency of hypertension and cardiovascular diseases, but unhappily this situation is far from being generalized.

\section{References}

1. Baker JL, Olsen LW, Sorensen TI. Childhood body-mass index and the risk of coronary heart disease in adulthood. N Engl J Med 2007; 357(23): 2329-37.

2. Moya M. Obesity and overweight interconnected hypertension-A common condition not to be overlooked since pediatric ages. Obes Control Ther. 2014; 1(2):1-2.

3. Moya M. Prevención precoz, prevención más eficaz. Un axioma para los estados comórbidos de la obesidad. Valencia (Spain): Real Academia de Medicina de la Comunidad Valenciana. 2014; 53-7.

4. Johansen A, Holm JC, Pearson S, Kjersgaard M, Larsen LM, Hojgaard $B$, et al. Danish clinical guidelines for examination and treatment of overweight and obese children and adolescents in a pediatric setting. Dan Med J. 2015; 62(5).pii:C5024.

5. Conliffe C, Franksom M, Smith F, Hanna-Mahase C, Oriakhi M. The Prevalence Of Elevated Blood Pressure In Adolescents In Nassau, The Bahamas. West Indian Med J. 2015; 64(1). doi: 10.7727/ wimj.2015.114.

6. Nkeh-Chungag BN, Sekokotla AM, Sewani-Rusike C, Namugowa A, Iputo JE. Prevalence of hypertension and pre-hypertension in 13-17 year old adolescents living in Mthatha- South Africa: A cross-sectional study. Cent Eur J Public Health. 2015; 23(1):59-64.

7. Flynn J. The changing face of pediatric hypertension in the era of childhood obesity epidemic. Pediatr Nephrol. 2013; 28(7):1059-66. doi: 10.1007/s00467-012-2344-0.

8. Erlingsdottir A, Indridason OS, Thordvalsson O, Edvardsson VO. Blood pressure in children and target-organ damage later in life. Pediatr Nephrol. 2010; 25(2):323-8. doi: 10.1007/s00467-009-1350-3.

9. Santi M, Simonetti BG, Leoni-Foglia CF, Bianchetti MG, Simonetti GD. Arterial hypertension in children. Curr Opin Cardiol. 2015; 30(4): 403-10. doi: 10.1097/HC0.0000000000000191.

10.Zhu H, Yan W, Ge D, Treiber FA, Harshfield GA, Kapuku G, et al. Relationship of cardiovascular phenotypes with healthy weight, at risk overweight and overweight in US youths. Pediatrics. 2008; 121(5):115-21. doi: 10.1542/peds.2006-3720.

11. Herrero BM, Keildson S, Lindgren CM. Genetics and epigenetics of obesity. Maturitas. 2011; 69(1):41-9. doi: 10.1016/j. maturitas.2011.02.018.

12. Dabelea D, Mayer-Davis EJ, Lamichhane AD. Association of intrauterine exposure to maternal diabetes and obesity with type 2 diabetes in youth: The SEARCH case-control study. Diabetes Care. 2008; 31(7):1422-6. doi: 10.2337/dc07-2417.

13. Smith J, Cianflone K, Biron S, Hould FS, Lebel S, Marceau S, et al. Effects of maternal surgical weight loss in mothers on intragenerational transmission of obesity. J Clin Endocr Metab. 2009; 94(11):4275-83. doi: 10.1210/jc.2009-0709. 
14. Waterland RA, Michels KB. Epigenetic epidemiology of the developmental origins hypothesis. Annu Rev Nutr. 2007; 27:363-88.

15. Kuczmarski RJ, Odgen CL, Guo SS, Grummer-Strawn LM, Flegal KM, Mei Z, et al. 2000 CDC growth charts for the United States: methods and development. Vital Health Stat 11. 2002; (246):1-190.

16. Cole TJ, Lobstein T. Extended international (IOTF) body mass index cut-offs for thinness, overweight and obesity. Pediatr Obes. 2012; 7(4):284-94. doi: 10.1111/j.2047-6310.2012.00064.x.

17. Geddes LA, Hoff HE, Badger AS. Introduction of the auscultatory method of measuring blood pressure--including a translation of Korotkoff's original paper. Cardiovasc Res Cent Bull. 1966; 5(2):5774.

18. Ingelfinger JR. The child or adolescent with elevated blood pressure. $\mathrm{N}$ Engl J Med. 2014; 371(11):1075. doi: 10.1056/NEJMc1408238.

19. National High Blood Pressure Education Program Working Group on High Blood Pressure in Children \& Adolescents. The fourth report on the diagnosis, evaluation, and treatment of high blood pressure in children and adolescents. Pediatrics 2004; 114 (2 Suppl. 4th Report):555-76.

20. Roth GA, Forouzanfar MH, Moran AE, Barber R, Nguyen G, Feigin VL, et al. Demographic and epidemiological drivers of global cardiovascular mortality. N Engl J Med. 2015; 372: 1333-41. doi: 10.1056/ NEJMoa1406656

21. Franks PW, Hanson RL, Knowler WC, Sievers ML, Bennet PH. Locker HC. Childhood obesity, other cardiovascular risk factors, and premature death. N Engl J Med. 2010; 362(6):485-93. doi: 10.1056/ NEJMoa0904130.

22. Thompson M, Dana T, Bougatsos C, Blazina I, Norris SL. Screening for hypertension in children and adolescents to prevent cardiovascular disease. Pediatrics 2013; 131(3): 490-525. doi: 10.1542/peds.20123523
23. Moyer VA. Screening for primary hypertension in children and adolescents: U.S. Preventive Services Task Force recommendation statement. Ann Intern Med. 2013; 159(9): 613-9. doi: 10.7326/00034819-159-9-201311050-00725.

24. Kaelber DC, Pickett F. Simple table to identify children and adolescents needing further evaluation of blood pressure. Pediatrics $2009 ; 123(6)$ : e972-4. doi: 10.1542/peds.2008-2680.

25. Moya M, Bosch VM. Hypertension- A sign to be screened for early on in overweight children and adolescents. IPA Newsletter. 2015; 10(2): $12-14$

26. de Onis M, Habicht JP. Anthropometric reference data for international use: recommendations from a World Health Organization Expert Committee. Am J Clin Nutr. 1996; 64(4):650-8.

27. Hirst J, Villar J, Kennedy S, Bhutta Z. On behalf of INTERGROWTH-21. Being born stunted and/ or wasted need not be inevitable. IPA Newsletter. 2015; 10(1):9-14.

28. Bobbioni-Harsch E, Pataky Z, Makoundou V, Laville M, Disse E, Anderwald C, et al. From metabolic normality to cardiometabolic risk factors in subjects with obesity. Obesity (Silver Spring). 2012; 20(10):2063-9. doi: 10.1038/oby.2012.69.

29. Calori G, Lattuada G, Piemonti L. Prevalence, metabolic features, and prognosis of metabolically healthy obese Italian individuals: the Cremona Study. Diabetes Care. 2011; 340:210-15. doi: 10.2337/ dc10-0665.

30. Tobish B, Blatniczki L, Barkai l. Cardiometabolic risk factors and insulin resistance in obese children and adolescents: relation to puberty. Pediatr Obes. 2015; 10(1):37-44. doi: 10.1111/j.20476310.2013.00202.x

31. Moya M, Juste M. Fatty liver disease among other comorbidities requiring early diagnosis in pediatric obesity. Obes Control Ther. 2013; 1(1):02. 